\title{
Autonoesis and Belief in a Personal Past: An Evolutionary Theory of Episodic Memory Indices
}

\author{
Stanley B. Klein
}

Published online: 3 April 2014

(C) Springer Science+Business Media Dordrecht 2014

\begin{abstract}
In this paper I discuss philosophical and psychological treatments of the question "how do we decide that an occurrent mental state is a memory and not, say a thought or imagination?" This issue has proven notoriously difficult to resolve, with most proposed indices, criteria and heuristics failing to achieve consensus. Part of the difficulty, I argue, is that the indices and analytic solutions thus far offered seldom have been situated within a well-specified theory of memory function. As I hope to show, when such an approach is adopted, not only does a new, functionally-grounded answer emerge; we also gain insight into the adaptive significance of the process proposed to underwrite our belief in the memorial status of a mental state (i.e., autonoetic awareness).
\end{abstract}

What justifies our feeling that the content of awareness refers to the past? How do we determine that our phenomenology is a veridical (or even partly compromised) representation of our past and not, say, a thought or act of imagination? Such questions have vexed philosophers and psychologists for almost as long as attention has been directed toward the (uniquely human; e.g., Suddendorf and Corballis 2007; Tulving 2005) act of recollection.

\section{The Philosophical Approach}

As philosophers have discovered (often in virtue of the responses of their critics; e.g., Coburn 1960; Furlong 1948, 1970; Urmson 1967; Von Leyden 1961), answers to the question of whether a mental state is an act of remembrance are hard to come by. Over the years numerous criteria and indices have been proposed for differentiating memorial from non-memorial content in awareness. Hume (1748/2004), for instance, argued that the vivacity of mental content is a means by which we can separate an image or thought from a memory, with memory being more "lively and vivacious". He also

S. B. Klein $(\square)$

Department of Psychological and Brain Sciences, University of California,

551 Ucen Road, Santa Barbara, CA 93106, USA

e-mail: klein@psych.ucsb.edu 
proposed that the amount of "free play" we have with our mental states serves as a criterion: In contrast to imagining, when we remember we have less free play, since that content is bound by the past to represent things as they actually were.

Locke (1689-1700/1975) took a less inferential approach, suggesting that memory has an intrinsic quality that directly signals awareness that experienced content belongs to a vanished time. Along similar lines, Reid argued that it is our unshakable belief in the pastness of an occurrent mental state that makes an experience one of memory rather than imagination: "...every man feels that he must believe what he distinctly remembers, though he can give no other reason for his belief but that he remembers the thing distinctly..." (Reid 1813/1969, pp. 325-326). Thus, both Locke and Reid, in contrast to Hume, felt that the pastness of an occurrent state need not be inferred from the presence of correlated indicators (e.g., vivacity or free play).

Turning to more recent treatments, Russell (1921) proposed that for mental content to be considered a memory it must be joined by two indices - feelings of pastness and familiarity. Holland (1954), by contrast, believed it unnecessary to assume that specific qualities must accompany, or be intrinsic to, an occurrent state to establish it as a memory. It is logically impossible, he maintained, to believe that we are remembering when in fact we are imagining, and vice versa. Accordingly, no "indicator" need accompany memory to justify its relation to the past: "If this idea is abandoned (i.e., that a memory requires indices to convey its status) then the need ceases to be felt for a specific experience which should function as an Indicator..." (Holland 1954; p. 485; words in parenthesis added for clarification). He continues, "One cannot, as Hume thought, contemplate an idea of the memory or an idea of the imagination and, feigning ignorance of their origins, begin to distinguish them afresh by means of a difference in their respective qualities" (p. 486).

Holland also took issue with Reid's contention that the only reason that can be offered for one's belief that a mental state is an act of remembering is that one remembers it distinctly. Treating the status of a mental state as a hypothesis amenable to empirical confirmation, Holland argued that when a memory (e.g., "I remember placing money in a box") is called into question, it is sufficient that we locate the box, open it and examine its contents. However, as Furlong (1951) and Von Leyden (1961) point out, the mere demonstration of the existence of a box containing funds cannot guarantee the veracity of my recollection. Such evidence "...does not bear on the correctness of my claim that it was I who put the money into the box, or that it was this box..." (Von Leyden 1961, p. 30). Holland's criterion for justification requires that verifying an occurrent mental state as a memory (i.e., of having placed money in a box), requires one remember (and thus located and examined) previously having placed the funds in the box. This empiricist "solution" thus begs the question by assuming what it is trying to prove.

Like Holland, Urmson (1967) felt that our belief in the memorial status of a mental state can be justified without recourse to qualities, marks or other indices. However, unlike Holland - who concentrated primarily on the case in which individuals respond to requests to remember - Urmson argues that our intention to recollect, regardless of whether that intention is in response to external demands or internal dynamics, is sufficient to establish that the content in awareness is a memory.

Unfortunately, both Holland and Urmson overestimated the extent to which experienced content issues from volitional acts of retrieval. Empirical research, as well as 
personal introspection, have shown that memories can, and often do, appear unbidden in awareness (for reviews see Berntsen 2009 and Salaman 1970). Verification criteria based on considerations of intentionality are not applicable to this non-trivial subset of recollective experience.

\section{The Psychological Approach}

Psychologists also have grappled with the problem of identifying the criteria we use to decide that mental content is an offering from memory (e.g., Johnson and Raye 1981; Loftus and Hoffman 1989; Roediger 1996; Schacter 2012; Schooler et al. 1986). Their objectives, however, are somewhat different from those found in philosophical treatments: While most philosophers attempt to identify conditions that are necessary and sufficient for determining that a mental state as a memory, psychologists largely eschew demands for certainty, focusing instead on inductively or introspectively defensible, heuristic solutions.

The main reason for this difference in approach traces to differences in conceptual precommitments: Though seldom explicitly voiced, philosophical analyses often are predicated on the assumption that memory provides a stable, veridical record of objects and events that transpired in the past. This assumption plays a significant role in determining the formative background of the questions philosophers ask of nature and the answers they find relevant. For example, on this view, it makes sense to inquire whether a "memory" is true or false (e.g., an imagination).

Psychological treatments, in contrast, typically do not trade in the distinction between truth and falsity. For academic psychologists, ${ }^{1}$ the content of memory can be (and typically is) different from the events which gave rise to it; memory, that is, is seen as constructive rather than reproductive. ${ }^{2}$ This idea, which has become commonplace among modern memory researchers (e.g., Loftus and Pickrell 1995; Neisser 1981; Nigro and Neisser 1983; Roediger 1996; Schacter 1995, 2012; for review see Danziger 2008), can be traced to work by Münsterberg (1909) and Bartlett (1932). These pioneers of the constructive approach documented that retrieved memory content is not a fixed and faithful transcription of the past, but rather a fluid, imaginative reconstruction that knits past experience with current beliefs, knowledge, motives, goals and even external suggestions to fill gaps in a less-than-permanent record. From this perspective, it does not make sense to compare the offerings of memory against the ideal of a literal record that can be revived by an act of recollection. Being reconstructed, these records cannot, in any simple sense, be "true".

\footnotetext{
${ }^{1}$ The view that memory is reconstructive characterizes "academic" psychological research, not psychological research in general. Among clinicians and neuroscientists memory is just as likely to be taken as a stable transcription of events as they originally transpired. Despite (a) Freud's realization that what initially he believed were patients' "true" recollections actually were fantasies (e.g., Schimek 1987), and (b), that after nearly a century (e.g., Penfield 1952), neuroscience finally appears ready to entertain the possibility that memory may not constitute a fixed transcription of the past (e.g., Schiller et al. 2010), the belief that recollection is underwritten by verdicial records still is the norm among these two disciplines.

${ }^{2}$ Interestingly, in antiquity memory was not taken to be a stable record of the past (e.g., Rubin 1995). It only was with the advent of transcription technology (e.g., writing, printing, cameras, tape recorders, computers, and so on) that the metaphor of permanence became part of our conception of the nature of memory (for discussion see Danziger 2008).
} 
Accordingly, concern with criteria based on binary oppositions (e.g., true or false; remembered or forgotten) shifted to a search for more dynamic indices better suited to capture the mutability of memory. Rather than focus on subjective indices or deductive principles that can establish the truth of retrieved content, psychologists were interested in the heuristics people used to support their belief that retrieved content was an offering from memory (note: the correlation between criteria - i.e., heuristic vs logical and academic domain - i.e., psychological vs philosophical - is far from unity. There are clear exceptions to the "rule" - e.g., Hume's strength/vividness criteria clearly resonates with several psychological proposals mentioned below). The heuristics they examined included such things as "ease of retrieval", "speed of retrieval", "item accessibility", "processing fluency" and the subjective qualities accompanying a mental state (e.g., Begg et al. 1989; Benjamin and Bjork 1996; Dunlosky and Nelson 1992; Johnson et al. 1988; Kelley and Jacoby 1996; Koriat 2000; Schooler et al. 1986; Schwarz et al. 1991; for a recent review see Dunlosky and Bjork 2008).

\section{Problems with Memory Criteria}

While philosophical answers to the question of how we identify a mental state as a memory have been creative and varied, each has been found to suffer from points of logical vulnerability and/or introspective counterexample (for reviews, see Bernecker 2010; Furlong 1951; Von Leyden 1961; Warnock 1987). Russell's and Hume's idea that the content of true recollection is "bound to the past" partly is undermined by the psychology's repeated demonstration that memory is not a fixed transcription of the past, but rather an assemblage consisting in additions to, subtractions from and other alterations of the past as experienced (e.g., Bartlett 1932; for reviews see Danziger 2008; Schacter et al. 1998). While Urmson's view that intentionality is a sufficient criterion may have limited warrant, he vastly underestimated how often memories come into awareness unaccompanied by any intention to remember (e.g., Berntsen 2009). Holland's empiricist criteria have the unfortunate consequence of begging the question (e.g., Furlong 1951). And, contra Hume, we all have had experiences in which an imagination is vivid (or lively) and a memory faint (or listless). In short, as Bernecker (2010) concludes, the trouble with the most memory-markers is that "they don't offer a reliable mark" (p. 22).

The presumption of "truth" is greatly relaxed in academic psychology: The question of whether methods or principles can be identified that can adjudicate whether a recollection faithfully captures a past occurrence is not the focal concern. What matters are the heuristics people use to support their belief that an occurent mental state is a memory, The discovery of phenomenal properties correlated with memory judgments (e.g., qualitative features, subjective feelings) and demonstrations that a variable (e.g., retrieval ease, processing fluency) can influence judgments are the primary bases by which memory heuristics have been identified.

There are, however, at least two problems with the psychological approach. First, finding that a variable can influence a memory judgment does not logically warrant the inference that the variable plays a role in judgments outside the experimental context. That is, there is no necessary equivalence between what a person can do and what he or she is designed (by natural selection) to do. This is the "function versus capability" distinction, discussed at length in Section 4. 
With respect to the issue at hand, the finding that a particular heuristics can be used to support a memory judgment does not license the conclusion that it would be recruited absent the demands - both explicit and implicit - of psychological testing. As is well-known, different variables can influence a system or process in ways that are measurably comparable, if not identical (i.e., multiple realizability; e.g., Kim 1998). Thus, the question is not whether a specific variable can be shown to possess a particular causal potency with regard to memory judgments; rather, it is whether those variables normally - as a consequence of the system's functional design - are recruited to accomplish that function.

A more general concern (one that applies to philosophical treatments as well) is that virtually all the justification criteria that have been proposed - heuristic as well as formal - are based on logical considerations (e.g., hypothesis testing), intuitions about how memory judgments are made (e.g., ease of retrieval, processing fluency, intentionality), and the discovery of subjective qualities correlated with reported recollections (e.g., richness of contextual and perceptual detail, feelings of pastness). In contrast, few, if any, of the heuristics, marks, criteria or indices thus far proposed are grounded in principles embodied in a well-specified theory of memory function.

In the next Section 1 present such a theory. Based on the assumption that memory is a biological system, and thus subject to selective pressures (e.g., Glenberg 1997; Klein 2007, 2013b; Klein et al. 2002; Nairne 2005; Sherry and Schacter 1987), I draw on evolutionary principles to guide theory construction. My focus is on naturally selected functional adaptations that enable us to treat an occurrent mental state as an act of recollection. Features of theory that do not bear directly on this issue - e.g., the neural localization of memory content, mechanisms underlying retrieval, properties of the systems of long-term memory - either are unaddressed or touched on briefly (in the service of advancing a particular argument). Readers interested in these omitted details will find fuller treatment in Klein (2013a, 2013b).

\section{Memory as a Biological System Designed by Natural Selection}

One way to study the functional design of a naturally selected system is to think of it as part of a machine, and then distinguish the machine's capabilities from its functions (e.g., Cosmides and Tooby 1992; Klein 2007; Klein et al. 2002). To specify a machine's function is to specify what it was designed to do. An example adapted from Klein et al. (2002) may help clarify the distinction between capability and function.

Imagine you are shown a three-hole punch. Having never seen one, you are not certain what it is. Unbeknownst to you, it has been designed to serve a specific function - to put holes in writing paper so the paper can be stored in a three-ring binder. If you knew this, it would help you understand why its parts exist in their present form: Why the punch has elements sharp enough to cut paper, why there are exactly three of them, why they form a straight line, and so on. These elements are design features - aspects of the punch that are there because they contribute to its function.

Yet every machine, in virtue of having a particular causal structure, is capable of doing many things it was not designed to do (i.e., by-products). If you shake a wellused three-hole punch, confetti falls out. The making of small circles of paper is a by- 
product of the machine's design: None of the punch's parts exist because that arrangement makes confetti. Had the machine been design to make confetti, one might expect more than just three elements, that their shape would be more in keeping with the festivities typically associated with the use of confetti (e.g., star-shaped), and so on. In short, confetti-making does not explain the presence or arrangement of the punch's parts. Nor do any of the punch's other capabilities - for example, its usefulness as a paper weight. These capabilities are arbitrary with respect to its function, the byproducts of the machine's design (e.g., Barkow et al. 1992; Williams 1966).

Studying memory by seeing what it is capable of doing - without asking what it was designed to do - is like studying a three-hole punch as if it were a confetti-maker (or a paper weight). It tells us what memory can do, but it does little to help us understand what memory was designed to do. Absent a consideration of aspects of design directed by natural selection, we essentially end up studying the "confetti of memory".

\subsection{The Functional Aspects of Long-Term Memory}

Memory is a system created by natural selection (e.g., Anderson 1991; Glenberg 1997; Klein 2013b, Nairine 2010; Klein et al. 2002; Nairne 2005; Sherry and Schacter 1987): It exists in its present form because that arrangement solved certain recurrent problems faced by the organism in its evolutionary past. Evolution does not produce new, complex, metabolically costly phenotypic systems by chance (e.g., Dawkins 1976; Mayr 2001; Williams 1966). Such systems acquire their functional organization because that specific design contributed to the organism's ability to survive and reproduce (e.g., Barkow et al. 1992; Klein 2013b; Sherry and Schacter 1987; Williams 1966). For an organism to behave more adaptively at a later time because of experiences at an earlier time, it must be equipped not only with mechanisms that retrieve ontogenetically acquired information, but the ability to direct that information toward environmental contingencies transpiring now and into the future (e.g., Klein 2013b; Schacter 2012).

On this view, many, if not most, features of memory have been designed by evolution to interface with systems for anticipation and planning (e.g., Bar 2011; Bradley 1887; Ingvar 1985; Klein 2007, 2013b; Klein et al. 2002, 2010, 2011; Llinas 2001; Suddendorf and Corballis 1997, 2007; Tulving 2005). As Klein and colleagues observe, "The adaptive function of information storage is intrinsically prospective: It is used to support future decisions and judgments, which cannot be known in advance with certainty. To the extent that the character of subsequent decisions and judgments can be predicted, the memory system can be tailored to flag relevant information and pre-compute variables that are required to make them." (Klein et al. 2002, p. 313: emphasis added).

This view of the subjective temporal orientation of memory has roots in the writings of Bradley (1887), who was among the first to challenge the dominant Aristotelian position that memorial experience was saddled to the past. In De Memoria Aristotle repeatedly made clear that the concern of memory exclusively is with things past: The object of memory "...is the past, not the future or present, nor what is present as an object of perception or theorizing." (De Memoria, reprinted in Sorabji 1972, p. 47).

Following Darwin's work on natural selection, Bradley adopted a functional analysis which challenged Aristotle's teachings on memory's subjective temporal orientation. 
Memory must, he argued, be oriented toward the future to ensure the adaptive success of its possessor: "Why is our memory directed towards our incoming sensations and towards the side from which change comes? .. . The answer, in a word, is practical necessity . . . Life being a process of decay and of continual repair and struggle throughout against dangers, our thoughts, if we care to live, must mainly go the way of anticipation. We are concerned practically with what meets us and what we go to meet, and this practical concern has formed the main habit of our thought." (Bradley 1887, pp. 581-582). In short, an evolved capacity to imagine and plan for future contingencies confers enormous selective advantages on its possessor (e.g., Boyer 2009; De Brigard 2013; Howe 2013; Klein et al. 2010, 2011, 2013b; Suddendorf et al. 2009; Schacter 2012; Tulving 2005; Young 1976).

All organisms capable of long-term memory are, of adaptive necessity, subjectively oriented toward the future (for review and evidence, see Klein 2013c, 2013b). What distinguishes humans from other sentient beings is that our anticipatory acts are more purposeful and proactive in response to their environment (e.g., Bischof-Koehler 1985; Klein 2013b, Suddendorf and Corballis 2007; Klein et al. 2010, 2011; Suddendorf and Corballis 1997). By virtue of this sophistication, our species, unlike others, can anticipate and plan for future contingencies in a manner that transcends current needs and motivational states (but see Cheke and Clayton 2010).

Accordingly, the most sober conclusion is that all organisms capable of memory are, of adaptive necessity, subjectively oriented toward the future (e.g., Boyer 2009; Ingvar 1985; Klein 2013b; Klein et al. 2002; Tulving 2005). Species-specific differences in future-orientation result from the complexity and temporal scope of anticipatory and planning abilities, not on their presence or absence (e.g., Klein 2013b; Suddendorf and Corballis 2007).

\subsection{Memory is of the Past But About the Future}

From an evolutionary perspective, the function of memory is to aid the organism in anticipating events and deciding the actions to take (e.g., Bernecker 2010; Bradley 1887; Ingvar 1985; Klein 2013b; Klein et al. 2002; Ludlow 1995; Tulving 2005). These abilities require an orientation toward the "now and the next": Life comes at organisms from the future, not from the past, and it is in that direction that effort must be directed.

Even memory-based responses to present contingencies necessarily are oriented toward the future. It is trivially true that all memory experiences are occurent - they are mental states happening "now". As Reid puts it, "Every man can distinguish the thing remembered from the remembrance of it. We may remember any thing we have seen, or heard, or known, of done, or suffered; but the remembrance of it is a particular act of the mind which now exists, and of which we are conscious" (Reid 1813/1969, pp 324-325).

But that is not what is at issue. While, on philosophical reflection, we might acknowledge that the presentation of memorial content to awareness is a presenttense affair, the normative stance - reflected in both folk conceptions of and professional dealings with memory - is that memory's function is to recapture (and thus be about) the past (for reviews see Danziger 2008; Draaisma 2000). This is seen in the way in which memory researchers typically approach their subject - i.e., the general 
adoption of methodologies focused on retentive capabilities and the accuracy of the content retrieved (reviews can be found in Puff 1982; Roediger 1996; Schacter 1995; Tulving and Craik 2000).

But even if we adopt the position that memory is about the present, I do not think this is supportable. As discussed at greater length in Klein (2013b), the notion of the "present" is poorly positioned - both conceptually and phenomenologically - to capture memory's temporal orientation. The "now" must, of computational necessity, transition to the "next" with an immediacy that is ontologically ungraspable (hence the need for the mathematical concepts such as the "limit") and experientially illusory.

While we may find the idea of the "present" to be a psychologically satisfying way of describing our relation with "now", our actual experience is not of the "now", but rather of a continual, uninterrupted flow of "nexts" (e.g., Husserl 1964; Loizou 1986). Analysis of the formal properties of the "present of objective time" reveals it to be instantaneous (e.g., Faye 1989; McLure 2005), becoming the next "present" essentially as soon as it makes an appearance (e.g., Husserl 1964; James 1890). It thus is a mistake to speak of the present in any way that implies measurable duration (e.g., Loizou 1986; McLure 2005): The present is a process consisting in an endless series of "nows" instantaneously transitioning to "nexts" (as well as retreating into the past; e.g., Husserl 1964). What is subjectively present necessarily is oriented toward, and phenomenologically indistinguishable from (i.e., instantaneous moments lack experiential resolution), what will be present - i.e., the future. Even the well-worn idea of a "specious present" (e.g., Husserl 1964; James 1890; Kelly 1882) requires inclusion of protention - i.e., orientation toward the "next" - as an essential aspect of the present.

In short, despite claims about the benefits of "living in the moment", this is a temporal orientation we cannot attain. The moment of the present is, formally speaking, instantaneous - an abstract point in a temporal continuum. Phenomenologically it is imperceptible: The "now" is continually, with undetectable rapidity, sliding toward the "next" and away from the past. On this view, memory experience must, of logical, ontological and phenomenological necessity, be oriented toward (i.e., about) the future (or, in the special case of episodic recollection, about the past; more on this curious, but important "exception to the rule" below). ${ }^{3}$

\subsection{Systems of Memory and their Subjective Temporal Orientation: A Brief Review}

Before proceeding, a few words are in order about the subjective temporality of the systems of long-term memory (a more detailed treatment can be found in Klein 2013b).

\footnotetext{
${ }^{3}$ The expanded temporality of the specious present represents time as moving toward the future as well as receding into the past (e.g., Husserl 1964; James 1890). On this basis, one might be concerned that I arbitrarily have chosen to focus on the future aspect of the specious present while ignoring its equally salient past aspect.

Two considerations inform my temporal focus. First, the principles of evolutionary functionality discussed earlier (see also Klein 2013b) argue that memory is shaped by selective pressures to deal with the oncoming contingencies, and thus oriented toward the future. In addition, the 2nd law of thermodynamics entails that physical laws are not symmetric to reversal of time's direction. Put simply, there is an "arrow of time" and it points in the direction of the future. Thus while past and future both are constituents of the specious present, the future aspect is accorded a privileged position in virtue of its relation to the law of cause and effect, entropy, etc.

In short, the contingent necessities of life as well as physical laws support my contention that the temporally relevant direction for a behaving organism (and hence for memory) is the future, not the past.
} 
Procedural long-term memory entails the utilization of learned skills (cognitive and physical). By contingent necessity, the exercise of those skills is future directed: "to behave" is to orient toward and prepare for impending contingencies, to engage in sequential acts and so on. Procedural memory is thus clearly oriented toward the "next".

Semantic memory makes knowledge available to awareness. Sometimes that knowledge is self-generated (e.g., "What is the name of that book?"; "Let's see, her phone number is..."); other times knowledge is cued externally by current contingencies (e.g., requests to share one's knowledge) or the interpretive aspect of perception (e.g., "that sound I am hearing must be a lawn mower"; "This object before me is a chair"). In all cases, the knowledge retrieved is in the service of current circumstances in instantaneous transition to, and continuation in, the future (even the act of retrieving words during a conversation is in the service of taking part in an ongoing event). One remembers a fact or identifies a sensation because these occurrent states enable one to participate in the forward moving circumstances of one's world.

Although content made available by semantic memory can refer to the past (e.g., "I now remember where I parked my car - although I can't recollect the act of parking"), these references are not directly given to awareness; rather they must be culled from the content of semantic knowledge by acts of inferences and interpretation (more on this in Sections 4.5 and 5.2). Quite often, this knowledge draws on the recollective ability of episodic memory to provide evidential support if justification either is requested or otherwise felt necessary to support an inference of pastness.

Episodic memory is a curious beast. Its most salient temporal feature is its recollective function (see Section 5), which provides us with a direct, unmediated sense that a "memory" of the past is indeed from the past (see Section 5.2). Other functions of episodic memory are future, rather than past oriented (e.g., prospection, scenario building, self-projection and other forms of future-oriented mental time travel that appear dependent on episodic memory; for recent reviews, see Klein 2013c; Schacter 2012: Suddendorf and Corballis 2007; Szpunar 2010). It is the recollective aspect of episodic memory that constitutes the sole "exception to the rule" that memory's subjective temporal orientation is toward the future. ${ }^{4}$

\footnotetext{
${ }^{4}$ A discussion of relation between future-oriented mental time travel (FMTT) and episodic memory would take us far afield. However, a few remarks will be helpful.

Despite clear theoretical argument and empirical demonstration that the future-oriented aspect of episodic memory is not the sole memory-based contributor to future-oriented temporal projection (e.g., Atance and O'Neill 2001; Klein et al. 2002), until recently FMTT research has been almost exclusively focused on the episodic aspects of FMTT. Only in the past few years have the contributions of semantic memory (as well as those of other cognitive mechanisms - e.g., Suddendorf et al. 2009) been recognized as critical aspects of future-oriented thought (for recent reviews, see Klein 2013c; Schacter 2012).

Accordingly, there is no reason to suppose that episodic memory bears a special relation to futureoriented cognition. Even when projective acts are self-referential (as opposed to impersonal imaginations about the state of the future), it now is known that patients lacking complete access to episodic memory can perform imaginative acts that entail the involvement of self in a future scenario (a recent summary of relevant data can be found in Klein 2013a, c).

What is special about episodic memory is that it alone among systems of memory is capable of directly presenting its owner the feeling that she or he is re-experiencing events from his or her past (more on this in Section 5). For remainder of this paper I will be concerned with this unique property of episodic memory. A more detailed treatment of the arguments for autonoetic functionality presented in this paper and their comparison with arguments of adaptive functionality that trade on the presumption of autonetic contributions to planning will be the subject of a forthcoming paper I am working on in conjunction with Endel Tulving.
} 


\subsection{Why is Memory Commonly Viewed as About the Past?}

As I have attempted to show (Klein 2013b), when nature is questioned with regard to memory's functional significance, the mode of subjective temporality with which memory is assumed to be associated (the past) is called into question: In contrast to the assumption of many philosophers and most psychologists, memory (in almost all its presentations) is not about the past. It is about the future (or the present transitioning into the future). It exists to guide our behavior in the face of contingencies that cannot be known with certainty. Thus, from an evolutionary perspective, memory's primary function is to enable its owner to face life as it comes, rather than to look back as it recedes. $^{5}$

Perhaps the main reason memory is associated with past-oriented subjectivity derives from a failure to appreciate that although memory's operations depend on past occurrences, such dependence does not logically warrant the inference that memory, as experienced, is about the past. A failure to separate the how of memory function from the purpose of memory function has led to the popular, but logically indefensible, presumption that memory, being of the past, must, of necessity, be about the past. While of implies "from" or "due to", about, in its functional sense, implies "for" or "directed toward" (about can also be taken to mean "concerning". This is not its functional sense, but rather its referential sense. As we will see in a later section of this paper, certain aspects of memory can refer to the past - e.g., episodic recollection but this is not memory's primary evolved function). As a result of this conflation, the exception is taken for the rule.

A second reason for the common acceptance of the past orientation of memory (there are others - e.g., cultural methods adopted to teach children about the function and use of memory; for discussion, see Klein 2013b) trades on the types of awareness held to be associated with different systems of long-term memory. In addition to shedding light on the temporal orientation of memory, a consideration of these differences will lead us back to the question that motivated this paper - "what indices do we rely on to decide whether a mental state is a memory?"

\subsection{Forms of Awareness Associated with Long-Term Memory}

The term "noesis" - which traces to the writings of early 20th century phenomenologists (e.g., Husserl 1964) - was introduced to psychology by Tulving (1985) in the course of explaining a distinction between temporal modes of consciousness which he called noetic and autonoetic awareness. A person who possesses autonoetic awareness "is capable of becoming aware of her own past as well as her own future; she is capable of mental time travel, roaming at will over what has happened as readily as over what might happen, independently of physical laws that govern the universe" (Tulving 1985, p. 5). This awareness "does not reside in memory traces as such; it emerges as the phenomenally apprehended product of the episodic memory system, autonoetic

\footnotetext{
${ }^{5}$ There has been recent movement to incorporate the future-orientation of memory into the mainstream research agenda (e.g., work on adaptive memory; for review see Nairine 2010, and future-oriented mental time travel; for reviews see Klein 2013a; Schacter 2012). These new approaches, however, remain exceptions to the received view that memory primarily is about the past.
} 
consciousness" (Tulving 2005. p. 17; for a related view see Klein 2013a; Klein and Nichols 2012).

Tulving distinguishes autonoetic consciousness from noetic consciousness - which is what "allows an organism to be aware of, and to cognitively operate on, objects and events, and relations among objects and events, in the absence of these objects and events" (Tulving 2005, p.1). Organisms possessing noetic consciousness are able to become aware of and "operate on" (i.e., orient toward the future) information unaccompanied by the feeling that they are re-experiencing the past.

Tulving regarded these distinctions as isomorphic with his distinction between episodic and semantic systems of memory (e.g., Tulving 1985, 2005; Wheeler et al. 1997). Only autonoesis is assumed capable of providing the subjective requirements for mental time travel (e.g., Suddendorf and Corballis 1997, 2007; Tulving 1985, 2005; Wheeler et al. 1997). Accordingly, only episodic memory is tied to temporally-rich autonoetic experience.

By contrast, the type of consciousness accompanying semantic memory (i.e., noetic) does not provide its owner with a subjective sense that she or he is mentally traveling back in time to the events and experiences that gave birth to the content in awareness. She or he may infer from an analysis of the content that the semantic memory refers to the past (e.g., "I know that saw a Jimi Hendrix concert when I was in high school, though I cannot recollect being there"), or by logical implication that knowledge present in awareness must have "come from somewhere" (e.g., "Hartford is the capital of Connecticut. I know that I learned this fact at some point in time, though I no longer remember where or when"). But these are acts of inference and interpretation that must be added to an occurrent mental state that is subjectively positioned to deal with the "now and the next".

Thus, only autonoetic consciousness is pre-reflective. It is directly given to awareness and does not require any further considerations or deliberations to justify one's feeling that the content in awareness is connected to the past (e.g., Klein 2013a; Markowitsch 2003; Tulving 2005). This distinction in the "modes of giveness" of the past to awareness is discussed more fully in the next section.

\section{The Special Case of Episodic Recollection}

Unlike other forms of long-term memory (e.g., semantic), the subjective temporal orientation of episodic recollection ${ }^{6}$ is toward past, not the present or (by logical implication - see Section 4.2) the future. Moeover, this feeling of pastness is directly given to awareness (e.g., Klein 2013a; Klein and Nichols 2012; Tulving 2005).

Semantic memory, in contrast, can focus one's attention on the past, but this temporal knowledge is not directly given to awareness. Rather it either is based on an interpretation of the content made available to consciousness (e.g., "I know that I

\footnotetext{
${ }^{6}$ Note: It is very important to keep in mind that episodic recollection is a subset (albeit a salient one) of the activities associated with episodic memory. The recollective act reunites the individual with his or her past. Other functions of episodic memory (e.g., foresight, simulation, self-projection) have a decidedly future orientation (for recent reviews see Addis and Schacter 2012; Klein 2013a). However, these functions are not unique to episodic memory. The recollective act, by contrast, is.
} 
was born in New York in 1952"), or is inferable from it (e.g., "Since I know that saw the movie Rocky, it must have been in the 1970s because...").

Episodic recollection thus occupies a unique position among types of memory with regard to its experienced connection to the past (e.g., Klein 2013a, 2013b; Markowitsch and Staniliou 2011; Tulving 1985, 2005): By virtue of autonoesis, it goes beyond the content presented, endowing the act of recollection with a direct, pre-reflective, and unmediated sense that one is re-living experiences of one's past. No additional mental gymnastics are required. Episodic recollection (by virtue of autonesis) thus differs from other types of memory experience in that it alone allows a person to feel directly connected to his or her past absent any mediation, interpretation, or inference (e.g., Klein 2013a; Klein and Nichols 2012; Tulving 2005). A person possessing autonoetic consciousness is capable of re-living experiences in their felt pastness. Episodic recollection is the only type of memory to be experientially wedded to the past in this manner (Klein 2013b; Tulving 1985, 2005).

In light of these considerations, we can see an additional reason why the subjective temporality of memory so often is assumed to be oriented toward the past. As a wealth of social psychological research has shown, the most salient members of a set have the highest likelihood of having their characteristics taken as properties of the whole (for review see Schneider 2004). Accordingly, we are disproportionately influenced in our assessment of memory's temporality by its most salient temporal feature - the autonoetic experience of mental transit to the past that accompanies recollection. For this reason, orientation toward the past can be expected to occupy a position of (inordinate) prominence in our beliefs about memory's subjective temporality. It also affects parental choice in communicating memory's temporal commitments to their children (for discussion, see Klein 2013c).

\subsection{Truth and Episodic Recollection: The Veracity of Memory is Not Targeted by Selective Pressures}

Evolution trades in functionality. With respect to memory, functionality requires only that memory work as designed, not that it remain faithful to some object or event from one's past. If what is remembered is sufficient to get the job done (e.g., to anticipate or plan for future contingencies), how it gets the job done is of considerably less concern (at least to nature; philosophers and neuroscientists may feel otherwise). Within the parameters provided by environmental regularities and the organisms' biological limitations, certain memory-based predictive abilities will work better than others. And those targets of natural selection, the ones that "work", are also the ones that will be passed to the next generation via sexual reproduction.

On this view, there is no principled reason for episodic recollection to adhere to any particular degree of fidelity to the past; all that matters, from a functional perspective, is that the information supplied is beneficial to the adaptive challenges faced by the organism. Indeed, recent treatments of "false memory" have begun to attribute many distortions to the operation of adaptive processes, rather than to some flaw inherent in the system (for a recent review see Schacter et al. 2011).

This is not to say that memory's content is unconstrained. To effectively and reliably solve problems, memory must maintain some degree of fidelity to the past. It would do no good, for example, to try to locate your parked car by recollecting an picture of the 
lunar landscape. Environmental regularities and the demands of reality place limits on which anticipatory behaviors will work, how well they will work, and which will fail. Nonetheless, within the (sometimes fairly broad) constraints imposed by reality, the memory content served up to consciousness need not entail "precision of match" to past events as a criterion of success.

That memory is a system for solving problems (e.g., Klein et al. 2002; Nairine 2010), rather than for faithfully reproducing past, is clearly reflected in the conception of memory as re-constructive rather than re-productive (e.g., Bartlett 1932). The constructivist position is given a much needed (but currently lacking) biological explanation by aligning it with the position that evolution tracks functionality, not truth (where "truth" is defined in some logically coherent manner).

In summary, although evolution obviously plays a part in the genesis of our uniquely human concerns with the concept of "truth" (evolution has, after all, provided us our intellect), this does not license the inference that "truth" is a target of natural selection. And, from an evolutionary perspective, that which is selected for is that which "works". If what "works" happens also to be "true" (by some criterion), all the better (e.g., Sellers and Schwartz 2013). But function does not require or track human notions of "truth".

\subsection{So, What is the Functional Significance of Episodic Recollection? Autonoesis as a Memory Index}

If episodic recollection is alone among memory experiences in virtue of its prereflectively given sense that one stands in direct relation to one's past (and it is - see Klein 2013b; see also the commentaries in the Journal of Applied Research in Memory and Cognition, Volume 3, Issue 4, in press), the question becomes "what is the functional significance of this phenomenological addendum?"

This is a difficult question. Popular suggestions, such as "episodic memory - and by extension, autonoesis - permit one to experience a sense of self-continuity" (e.g., Conway 2005; Locke 1689-1700/1975; Sani 2008) are neither empirically compelling nor logically convincing (as was noted almost immediately following Locke 1689-1700/1975, who offered the first detailed philosophical treatment of the idea that personal identity is a function of memory; for critiques, se Butler 1736/1819; Reid 1813). Although modern treatments of personal identity continue to rely heavily on episodic memory as the evidential basis of self-continuity (for reviews see Fivush and Haden 2003; Sani 2008), serious problems remain (for a recent summary and discussion of the empirical evidence in support of this assertion, see Klein 2013d).

What then is autonoesis for? I suggest the following possibility. But first, a little history. According to the original criteria proposed to distinguish episodic from semantic long-term memory (Tulving 1972), the content of episodic, but not semantic memory makes explicit reference to three contextual features associated with the act of learning - i.e., time, space and self. Unfortunately, the utility of this 3-pronged scheme has been called into question: An extensive body of evidence now shows that semantic as well as episodic memory can contain information about the temporal, spatial, and self-referential properties of a remembered experience (for recent reviews, see Klein et al. 1989; Klein and Gangi 2010; Klein and Lax 2010; Kopelman et al. 1989; Martinelli et al. 2013; Renoult et al. 2012). Thus, the "time, space and self" criterion 
for distinguishing between semantic and episodic memory has been found insufficient for the task for which it was designed.

Partly in response to this blurring of criteria, Tulving (1985) supplemented his original classificatory system by endowing episodic memory with a unique form of consciousness called autonoetic awareness. In this way, he provided a phenomenological (as opposed to a contextual) basis for distinguishing episodic from semantic memory (semantic memory, as we have seen, was held to make possible a form of awareness Tulving termed noetic).

The primary intent to the autonoetic/noetic hypothesis was to address problems with the 3-property criterion for classifying episodic and semantic memory. In this regard it has proven quite successful (e.g., Markowitsch and Staniliou 2011; Vandekerckhove and Panksepp 2009; Tulving 2005). It was not, however, intended to address questions of functionality: Accordingly, the adaptive benefits of episodic recollection remain unresolved.

If episodic recollection enables its possessor to re-live his or her past, what selective advantage does such ability confer? Being consciously aware of events that took place minutes, weeks or years earlier has its advantages (for discussion and related empiricism, see Klein et al. 2001, 2002, 2009; Tulving 2005). Most of these have to do with the social aspects of life (self-knowledge, social interactions; e.g., Boyer 2009; Klein et al. 2001, 2009; Klein and Gangi 2010). But the question remains - "What benefit does recollection provide that could not be had from knowledge of memory content absent the experience of re-living the conditions surrounding the acquisition of that knowledge?" Why cannot the same, or comparable, benefits be obtained from noetically informed semantic knowledge of time, place and self?

The answer, I believe, pivots on a fuller appreciation of the type of subjectivity associated with episodic recollection. Considered in conjunction with the position that the veracity of memory is not targeted by selective pressures (see Section 5.1), autonoesis may be evolution's solution to the problem of how we decide whether our memories of the past are trustworthy. Clearly, there are advantages to believing that one's memories make contact with a past "reality". If we could not act on our recollections without first having to analyze them for veracity, valuable time would be lost for responding to environmental contingencies. This would be particularly true with respect to animate aspects of the environment, which often do not provide us the luxury of rational analysis prior to acting. If we were unable to take it as axiomatic that our recollections reflected something that actually transpired, both our confidence in our ability to deal with "reality" and our capacity to do so in a timely manner would be seriously compromised. This would not bode well for survival, especially in situations in which a quick response is required.

Autonoetic awareness (not memory content, per se), I suggest, may be the source of our confidence that our recollections track the past, and thus our ability to deal promptly and effectively with the circumstances for which recollection was naturally selected (e.g., future-oriented responses). That is, autonoetic awareness is the awareness that an occurrent mental state is tied directly to past experience. Autonoesis informs consciousness in an automatic, pre-reflective manner that the content of a recollection is "tied to its source in one's past" (impairment of autonoesis has the consequence that fully contextualized and personally relevant memory content is treated as alien to the self - i.e., it is felt not to be a recollection; e.g., Klein 2013a, 2014; Klein and Nichols 2012). 
The extent to which this informative function is faithful to the past is a separate issue. While "truth" is not a focus of natural selection, internal and external regularities and contingencies place limits on the degree to which our acts are given free reign. When the gap between belief/act and "reality" grows too wide, adaptive liabilities insure that such "flights of fancy" result in negative reproductive consequences.

But this much is clear - unlike the offerings of other types of long-term memory (e.g., semantic, procedural), we do not have to infer, search for indices, use heuristics, consider properties, or otherwise determine that the content of a recollection is about the past (of course, we can and often do so - provided the circumstances surrounding the act of recollection permit us the luxury of exercising our analytic skills); rather its pastness is directly, pre-reflectively given to awareness as a representation of events that took place in one's life. In this sense, it provides the experiencer with an immediate sense that the content of awareness derives from an experience in his or her personal past.

By contrast, semantic-memory based mental content is noetic. Its relation to one's past must be inferred from the context embedded within the content of the occurrent mental state, or from knowledge that one is intentionally attempting to remember (e.g., Urmson 1967). But the word "remembering", used in this sense, is more linguistic habit than an experiential index. There is no principled difference between experiencing the content of imagination or thought and experiencing the content of semantic memory (e.g., Klein 2013a). In each case, the phenomenology is that of content stripped of any sense of reliving the temporal, spatial or self-referential aspects of a previous experience.

What is phenomenologically salient is the effort required to make such content available to consciousness. Whether that effort has been directed toward semantic memory (as opposed to a thought or imagination) is something one can and might consider given an internal or external motivation to do so (e.g., I am trying to remember?; I am being asked to remember?); but the experience of content, per se, does not require, entail or confer a sense that my awareness is directed at an act of memory. It is only episodic recollection that, by virtue of autonoetic awareness accompanying the act of recollection, comes with a "mark" that directly presents that act to consciousness as an act of memory.

In summary, autonoesis provides us with a direct and unmediated "sense or feeling of certainty" that occurrent mental content portrays the past. There is no need for additional inferential or inductive work that is required to verify the content presented to consciousness via noetic awareness. Consistent with this proposal, evidence from the "remember - know" paradigm (for a review of the evidence and critical discussion, see Dunn 2004) shows that participants' feelings of confidence in the accuracy of remembered content are considerably higher when the self-identified basis for retrieval is "I remember" (i.e., autonoetic) than when it is "I know" (i.e., noetic).

\section{But Am I Begging the Question?}

One might be concerned that my approach to episodic recollection begs the question of what makes the experience of recollection felt as "being of the past" (in much the same way that earlier theories positing a "feeling of pastness" or other such internal indices 
did). Specifically, am I simply stipulating that autonoesis conveys pastness, and then using that stipulation to support my thesis that autonoetic awareness provides a direct "mark" of the pastness of an occurrent mental state?

While this concern has philosophical legitimacy, this is an instance in which appeal to psychological empiricism can mitigate the force of a conceptual issue. In a series of papers (e.g., Klein 2013a; Klein and Nichols 2012) my colleagues and I have reported the case of amnesic patient R.B. Unlike most patients suffering from episodic amnesia, R.B.'s memory issues are very uncommon (I know of only one comparable case Talland 1964). R.B. is capable of remembering events from his life with the contextual detail of an act of episodic recollection. For example, in response to a request to remember a specific time involving his experiences as a child, he replied:

"I can see the scene in my head. I (am) remembering scenes, not facts...I am recalling scenes...that is...I can clearly recall a scene of me at the beach in New London with my family as a child. But the feeling was that the scene is not my memory. As if I was looking at a photo of someone else's vacation."

He continues:

"I can recall memories at will. I have normal control over remembering facts and scenes from my past. But when I remember scenes from before the injury (he suffered a severe head injury in a bicycle accident), they do not feel as if they happened to me - though intellectually I know they did."

These memories (which are reported more fully in Klein and Nichols 2012) show all the hallmarks of episodic recollection save for the notable absence of a sense of autonoetic awareness: They contain temporal, spatial and self-referential contextual elements that accurately track (accuracy was obtained via third party reports) the manner in which the original learning transpired. What is lacking, however, is a feeling that the content of awareness is an actual memory that took place in the patient's personal past. That is, his autonoetic awareness is impaired. Thus, despite occurrent content that fits all the criteria for episodic recollection (detailed analysis of R.B.'s memory reports and support for the argument that his recollective acts are indeed episodic and not imaginations or semantic abstractions, can be found in Klein 2013a and Klein and Nichols 2012. It also is useful to note that he eventually recovered his autonoetic abilities, at which time the same "episodic content" was now given to consciousness as a personal recollection), R.B. does not feel as though the mental state he experiences is a personal memory.

The unusual nature of this case is likely to stimulate a host of questions about both self and memory. Many of these issues have been addressed in the references cited and I refer the interested reader to those sources. For present purposes, the important points are (a) autonoetic awareness is not intrinsic to the act of episodic remembering (as Tulving 2005, hypothesized); content that contains all of the criterial features of episodic recollection can be present in consciousness and yet not be directly given to experience as a reliving of one's personal past (R.B. notes on several occasions that he relies on inferential processes to decide that the content in consciousness must be something he personally experienced), (b) the same content can be taken as "not my own past" or "my own past" (i.e., before and 
after his autonoetic impairment resolved), and (c) the finding that autonoetic awareness is contingently related to episodic-like content, and that the two can come apart under conditions of pathology, suggests the autonoesis can serve as a useful criterion for "marking" occurrent mental content as personal memory, and that its utility in this regard is not dependent simply on stipulation (note: there are a number of related psychological conditions that show similar separability of content and personal ownership in domains other than memory - e.g., schizophrenic thought insertion, depersonalization disorders, pain asymbolia; for extensive discussion, see Klein 2014). Clearly, the case of R.B. is not a "knock-down" argument against the tautology concern - but is does afford a (potentially) independent means of linking autonoesis to felt pastness.

\section{Final Thoughts}

What we observe of nature are those aspects revealed by the questions we ask (e.g., Bohr 1958; Heisenberg (1958/1999). It therefore is important that we ask the "right" questions of nature. As Heisenberg (1958/1999) noted, "asking the right question is frequently more than halfway to the solution of the problem" (p. 35). If the questions posed are not the "right" ones, the answers received will lack the resolution necessary to fine-tune our understanding of the object of inquiry.

But, how do we know what constitutes the "right" question? The obvious answer is that theory guides our selection. A well-formulated theory grounds our inquiries by clarifying our conceptual analysis and specifying the experimental conditions needed to ensure that nature "pushes back" with answers that address our concerns (e.g., Brunswik 1947/1956; Godfrey-Smith 2003; Klee 1997).

Granting that memory is a property of organic matter, the principles of natural selection seem well-positioned to serve as criteria for determining whether the questions we addressed to nature are the "right" sort. Adoption of evolutionary criteria has the additional, salutary consequence of supplementing questions that probe memory's capabilities (which have been the focus of most modern research; for discussion, see Klein 2007, 2013b; Klein et al. 2002) with questions concerned with its evolved function. When interrogated with respect to function, the answers nature provides can be quite unexpected.

The question asked in this paper is one of central importance in memory research "How does a person know that an occurrent mental state is a memory as opposed to, say, a thought or an act of imagination?" Although this has been a focus of philosophical and psychological inquiry for centuries, most of the answers proposed suffer from conceptual and empirical ambiguities. Logical shortcomings and counterexamples compromise most philosophical offerings. With regard to psychological approaches, the failure to clearly situate proposed criteria within a theory of memory function has the effect of blurring the distinction between the variables people can use and the variables they were designed by natural selection to use to support their belief that a mental state is a recollection.

However, when the question is formulated under the guidance of a well-specified, evolutionarily-grounded theory of memory function, not only do new answers emerge, but we also gain insight into the adaptive significance of the processes that underwrite 
our belief in the memorial status of a mental state. Specifically, as I have argued, the autonoetic awareness accompanying (but not intrinsic to: Klein and Nichols 2012; Tulving 2005) episodic recollection provides us with a direct, pre-reflective feeling that an occurrent mental state is indeed a memory.

As an additional benefit accruing from interrogating memory from the perspective of its evolutionarily-mediated functional relevance, an answer also emerges to the question of recollection's adaptive significance. Specifically, recollection enables its possessor to interact with nature with confidence that his or her responses are based on remembrance of things past and not on imaginative creations (though, as we have seen, the "truth" of the recollected content typically lies somewhere in-between).

\section{References}

Addis, D.R., and D.L. Schacter. 2012. The hippocampus and imagining the future: Where do we stand? Frontiers in Human Neuroscience 5: 173.

Anderson, J.R. 1991. Is human cognition adaptive? Behavioral and Brain Sciences 14: 471-517.

Atance, C.M., and D.K. O’Neill. 2001. Episodic future thinking. Trends in Cognitive Science 5: 533-539.

Bar, M. 2011. Predictions and the brain: Using our past to generate a future. New York: Oxford University Press.

Barkow, J.H., L. Cosmides, and J. Tooby (eds.). 1992. The adapted mind: Evolutionary psychology and the generation of culture. New York: Oxford University Press.

Bartlett, F.C. 1932. Remembering. London: Cambridge at The University Press.

Begg, I., S. Duft, P. Lalonde, R. Melnick, and J. Sanvito. 1989. Memory predictions based on ease of processing. Journal of Memory and Language 28: 610-632.

Benjamin, A.S., and R.A. Bjork. 1996. Retrieval fluency as a metacognitive index. In Implicit memory and metacognition, ed. L.M. Reder, 309-338. Hillsdale: Erlbaum Publishers.

Bernecker, S. 2010. Memory: A philosophical study. Oxford: Oxford University Press.

Berntsen, D. 2009. Involuntary autobiographical memories: An introduction to the unbidden past. Cambridge: Cambridge University Press.

Bischof-Koehler, D. 1985. On the phylogeny of human motivation. In Emotion and reflexivity, ed. L.H. Eckensberger and E.D. Lantermann, 3-47. Vienna: Urban \& Schwarzenberg.

Bohr, N. 1958. Atomic physics and human knowledge. New York: Wiley.

Boyer, P. 2009. What are memories for? Functions of recall in cognition and culture. In Memory in mind and culture, ed. P. Boyer and J.V. Wertsch, 3-28. Cambridge: Cambridge University Press.

Bradley, F.H. 1887. Why do we remember forwards and not backwards? Mind 12: 579-582.

Brunswik, E. 1947/1956. Perception and the representative design of psychological experiments. Berkeley: University of California Press.

Butler, J. 1736/1819. Of personal identity. In The analogy of religion, ed. J. Angus, 211-215. London: Allman and Sawers.

Cheke, L.G., and N.S. Clayton. 2010. Mental time travel in animals. WIREs Cogntive Science 1: 1-16.

Coburn, R.C. 1960. A defect in Harrod's inductive justification of memory. Philosophical Studies 11: 81-85.

Conway, M.A. 2005. Memory and the self. Journal of Memory and Language 53: 594-628.

Cosmides, L., and J. Tooby. 1992. Cognitive adaptations for social exchange. In The adapted mind: Evolutionary psychology and the generation of culture, ed. J. Barkow, L. Cosmides, and J. Tooby, 163-228. New York: Oxford University Press.

Danziger, K. 2008. Marking the mind: A history of memory. Cambridge: Cambridge University Press.

Dawkins, R. 1976. The selfish gene. Oxford: Oxford University Press.

De Brigard, F. 2013. Is memory for remembering? Recollection as a form of episodic hypothetical thinking. Synthese. doi:10.1007/s11229-013-0247-7.

Draaisma, D. 2000. Metaphors of mind: A history of ideas about the mind. New York: Cambridge University Press.

Dunn, J.C. 2004. Remember-know: A matter of confidence. Psychological Review 111: 524-542.

Dunlosky, L., and R.A. Bjork. 2008. Handbook of metamemory and memory. New York: Psychology Press.

Dunlosky, J., and T.O. Nelson. 1992. Importance of the kind of cue for judgments of learning (JOLs) and the delayed-JOL effect. Memory and Cognition 20: 373-380. 
Faye, J. 1989. The reality of the future. Odense: Odense University Press.

Fivush, R., and C.A. Haden. 2003. Autobiographical memory and the construction of a narrative self. Mahwah: Lawrence Erlbaum Associates.

Furlong, E.J. 1948. Memory. Mind 57: 16-44.

Furlong, E.J. 1951. A study in memory: A philosophical essay. London: Thomas Nelson and Sons.

Furlong, E.J. 1970. Mr. Urmson on memory and imagination. Mind 79: 137-138.

Glenberg, A.M. 1997. What memory is for? Behavioral and Brain Sciences 20: 1-55.

Godfrey-Smith, P. 2003. Theory and reality. Chicago: University of Chicago Press.

Heisenberg, W. 1958/1999. Physics and philosophy. Amherst: Prometheus Books.

Holland, R.F. 1954. The empiricist theory of memory. Mind 63: 464 486.

Howe, M.L. 2013. Securing the future by remembering the past: But just when does this past and future begin to develop? Journal of Applied Research in Memory and Cognition 2(4): 237-239.

Hume, D. 1748/2004. An enquiry concerning human understanding. New York: Dover Publications.

Husserl, E. 1964. The phenomenology of internal time-consciousness. Bloomington: Indiana University Press.

Ingvar, D.H. 1985. Memory of the future: An essay on the temporal orientation of conscious awareness. Human Neurobiology 4: 127-136.

James, W. 1890. Principles of psychology. New York: Henry Holt and Company.

Johnson, M.K., \& Raye, C.L. (1981). Reality monitoring. Psychological Review 88: 67-85.

Johnson, M.K., M.A. Foley, A.G. Suengas, and C.L. Raye. 1988. Phenomenal characteristics of memories for perceived and imagined autobiographical events. Journal of Experimental Psychology: General 117: 371-376.

Kelley, C.M., and L.L. Jacoby. 1996. Memory attributions: Subjective experience versus analytic bases for judgments. Journal of Memory and Language 35: 157-175.

Kelly, E.R. 1882. The alternative: A study of psychology. London: Macmillian.

Kim, J. 1998. Mind in a physical world: An essay on the mind-body problem and mental causation. Cambridge: MIT Press.

Klee, R. 1997. Introduction to the philosophy of science: Cutting nature at its seams. New York: Oxford University Press.

Klein, S.B. 2007. Phylogeny and evolution: Implications for understanding the nature of a memory system. In Science of memory: Concepts, ed. H.L. Roediger, Y. Dudai, and S. Fitzgerald, 377-381. New York: Oxford University Press.

Klein, S.B. 2013a. Making the case that episodic recollection is attributable to operations occurring at retrieval rather than to content stored in a dedicated subsystem of long-term memory. Frontiers in Behavioral Neuroscience 7: 3. doi:10.3389/fnbeh.2013.00003

Klein, S.B. 2013b. The temporal orientation of memory: It's time for a change of direction. Journal of Research in Applied Memory and Cognition 2: 222-234.

Klein, S.B. 2013c. The complex act of projecting oneself into the future. WIREs Cognitive Sciences 4: 63-79.

Klein, S.B. 2013d. The sense of diachronic personal identity. Phenomenology and the Cognitive Sciences 12: 791-811.

Klein, S.B. 2014. The two selves: Their metaphysical commitments and functional independence. New York: Oxford University Press.

Klein, S.B., and C.E. Gangi 2010. The multiplicity of self: Neuropsychological evidence and its implications for the self as a construct in psychological research. The Year in Cognitive Neuroscience 2010: Annals of the New York Academy of Sciences, 1191, 1-15.

Klein, S.B., and M.L. Lax. 2010. The unanticipated resilience of trait self-knowledge in the face of neural damage. Memory 18: 918-948.

Klein, S.B., and S. Nichols. 2012. Memory and the sense of personal identity. Mind 121: 677-702.

Klein, S.B., J. Loftus, and H.A. Burton. 1989. Two self-reference effects: The importance of distinguishing between self-descriptiveness judgments and autobiographical retrieval in self-referent encoding. Journal of Personality and Social Psychology 56: 853-865.

Klein, S.B., L. Cosmides, J. Tooby, and S. Chance. 2001. Priming exceptions: A test of the scope hypothesis in naturalistic trait judgments. Social Cognition 19: 443-468.

Klein, S.B., L. Cosmides, J. Tooby, and S. Chance. 2002. Decisions and the evolution of memory: Multiple systems, multiple functions. Psychological Review 109: 306-329.

Klein, S.B., L. Cosmides, C.E. Gangi, B. Jackson, J. Tooby, and K.A. Costabile. 2009. Evolution and episodic memory: An analysis and demonstration of a social function of episodic recollection. Social Cognition 27: 283-319.

Klein, S.B., T.E. Robertson, and A.W. Delton. 2010. Facing the future: Memory as an evolved system for planning future acts. Memory \& Cognition 38: 13-22. 
Klein, S.B., T.E. Roberson, and A.W. Delton. 2011. The future-orientation of memory: Planning as a key component mediating the high levels of recall found with survival processing. Memory 19: 121-139.

Kopelman, M.D., B.A. Wilson, and A.D. Baddeley. 1989. The autobiographical memory interview: A new assessment of autobiographical and personal semantic memory in amnesic patients. Journal of Clinical and Experimental Neuropsychology 11: 724-744.

Koriat, A. 2000. The feeling of knowing: Some metatheoretical implications for consciousness and control. Consciousness and Cognition 9: 149-171.

Llinas, R.R. 2001. I of the vortex: From neuron to self. Cambridge: MIT Press.

Locke, J. 1689-1700/1975. An essay concerning human understanding. Oxford: Clarendon Press.

Loftus, E.F., and H.G. Hoffman. 1989. Misinformation and memory: The creation of memory. Journal of Experimental Psychology: General 118: 100-104.

Loftus, E.F., and J.E. Pickrell. 1995. The formation of false memories. Psychiatric Annals 25: 720-725.

Loizou, A. 1986. The reality of time. Aldershot: Gower Publishing Co.

Ludlow, P. 1995. Social externalism and memory: A problem? Acta Analytica 10: 69-76.

Markowitsch, H.J. 2003. Autonoetic consciousness. In The self in neuroscience and psychiatry, ed. T. Kircher and A. David, 180-196. Cambridge: Cambridge University Press.

Markowitsch, H.J., and A. Staniliou. 2011. Memory, autonoetic consciousness, and the self. Consciousness and Cognition 20: 16-39.

Martinelli, P., M. Sperduti, and P. Piolino. 2013. Neural substrates of the self- memory system: New insights from a meta-analysis. Human Brain Mapping 34: 1515-1529. doi:10.1002/hbm.22008.

Mayr, E. 2001. What evolution is. New York: Basic Books.

McLure, R. 2005. The philosophy of time. New York: Routledge.

Münsterberg, H. 1909. On the witness stand: Essays on psychology and crime. New York: Doubleday.

Nairine, J.S. 2010. Adaptive memory: Evolutionary constraints on remembering. In The psychology of learning and motivation, Vol. 53, ed. B.H. Ross, 1-32. London: Academic.

Nairne, J.S. 2005. The functionalist agenda in memory research. In Experimental cognitive psychology and its applications: A Festschrift in honor of Lyle Bourne, Walter Kintsch and Thomas Landaur, ed. A.F. Healy, 115-126. Washington DC: American Psychological Association.

Neisser, U. 1981. John Dean's memory: A case study. Cognition 9: 1-22.

Nigro, G., and U. Neisser. 1983. Point of view in personal memories. Cognitive Psychology 15: 467-482.

Penfield, W. 1952. Memory mechanisms. AMA Archives of Neurology \& Psychiatry 67: 178-198.

Puff, C.R. 1982. Handbook of research methods in human memory and cognition. New York: Academic.

Reid, T. 1813/1969. Essays on the intellectual powers of man. Cambridge: MIT Press.

Renoult, L., P.S.R. Davidson, D.J. Palombo, M. Moscovitch, and B. Levince. 2012. Personal semantics: At the crossroads of semantic and episodic memory. Trends in Cognitive Sciences 16(11): 550-558.

Roediger, H.L. 1996. Memory illusions. Journal of Memory and Language 35: 76-100.

Rubin, D.C. 1995. Memory in oral traditions: The cognitive psychology of epic, ballads, and counting-out rhymes. New York: Oxford University Press.

Russell, B. 1921. The analysis of mind. London: George Allen and Unwin, Ltd.

Salaman, E. 1970. A collection of moments: A study of involuntary memory. New York: St. Martin's Press.

Sani, F. 2008. Self continuity: Individual and collective perspectives. New York: Psychology Press.

Schacter, D.L. 1995. Memory distortion. Cambridge, MA: Harvard University Press.

Schacter, D.L. 2012. Adaptive constructive processes and the future of memory. American Psychologist 67: 603-613.

Schacter, D.L., K.A. Norman, and W. Koutstaal. 1998. The cognitive neuroscience of constructive memory. Annual Review of Psychology 49: 289-318.

Schacter, D.L., S.A. Guerin, and P.L. St. Jacques. 2011. Memory distortion: An adaptive perspective. Trends in Cognitive Sciences 15: 467-474.

Schiller, D., M. Monfils, C.M. Raio, D. Johnson, J.E. LeDoux, and E.A. Phelps. 2010. Blocking the return of fear in humans using reconsolidation update mechanisms. Nature 463: 49-53.

Schimek, J.G. 1987. Fact and fantasy in the seduction theory: A historical review. Journal of the American Psychoanalytic Association 35: 937-965.

Schneider, D.J. 2004. The psychology of stereotyping. New York: The Guildford Press.

Schooler, J.W., D. Gerhard, and E.F. Loftus. 1986. Qualities of the unreal. Journal of Experimental Psychology: Learning, Memory, and Cognition 12: 171-181.

Schwarz, N., H. Bless, F. Strack, G. Klumpp, H. Rittenauer-Schatka, and A. Simons. 1991. Ease of retrieval as information: Another look at the availability heuristic. Journal of Personality and Social Psychology 61: 195-202. 
Sellers, P.D., and B.L. Schwartz. 2013. Episodic-like animals, functional faces, and a defense of accuracy. Journal of Applied Research in Memory and Cognition 4(2): 243-245.

Sherry, D.F., and D.L. Schacter. 1987. The evolution of multiple memory systems. Psychological Review 94 : 439-454.

Sorabji, R. 1972. Aristotle on memory. Providence: Brown University Press.

Suddendorf, T., and M.C. Corballis. 1997. Mental time travel and the evolution of the human mind. Genetic, Social, and General Psychology Monographs 123: 133-167.

Suddendorf, T., and M.C. Corballis. 2007. The evolution of foresight: What is mental time travel, and is it unique to humans? Behavioral and Brains Sciences 30: 299-313.

Suddendorf, T., D.R. Addis, and M.C. Corbaillis. 2009. Mental time travel and the shaping of the mind. Philosophical Transactions of the Royal Society B 364: 1317-1324.

Szpunar, K.K. 2010. Episodic future thought: An emerging concept. Perspectives on Psychological Science 5: $142-162$.

Talland, G.A. 1964. Self-reference: A neglected component in remembering. American Psychologist 19: 351353.

Tulving, E. 1972. Episodic and semantic memory. In Organization of memory, ed. E. Tulving and W. Donaldson, 381-403. New York: Academic.

Tulving, E. 1985. Memory and consciousness. Canadian Psychology/Psychologie Canadienne 26: 1-12.

Tulving, E. 2005. Episodic memory and autonoesis: Uniquely human? In The missing link in cognition: Origins of self-reflective consciousness, ed. H.S. Terrace and J. Metcalfe, 3-56. Oxford: Oxford University Press.

Tulving, E., and F.I.M. Craik. 2000. The Oxford handbook of memory. Oxford: Oxford University Press.

Urmson, J.O. 1967. Memory and imagination. Mind 76: 83-91.

Vandekerckhove, M., and P. Panksepp. 2009. The flow of anoetic to noetic and autonoetic consciousness: A vision of unknowing (anoetic) and knowing (noetic) consciousness in the remembrance of things past and imagined futures. Consciousness and Cognition 18: 1018-1028.

Von Leyden, W. 1961. Remembering: A philosophical problem. New York: Philosophical Library, Inc.

Warnock, M. 1987. Memory. Boston: Faber and Faber.

Wheeler, M.A., D.T. Stuss, and E. Tulving. 1997. Toward a theory of episodic memory: The frontal lobes and autonoetic consciousness. Psychological Bulletin 121: 331-354.

Williams, G.C. 1966. Adaptation and natural selection: A critique of some current evolutionary thought. Princeton: Princeton University Press.

Young, J.Z. 1976. The evolution of memory. Burlington: Carolina Biological Supply Company, Scientific Publication Division. 